\title{
Prvé hniezdenie dážd'ovníka skalného (Tachymarptis melba) na Slovensku
}

\author{
First breeding record of the Alpine Swift (Tachymarptis melba) \\ in Slovakia
}

\section{Matej Repel $^{1 *}$, Peter Chrašč $\check{c}^{1} \&$ Emil Palkoci ${ }^{2}$}

\author{
${ }^{1}$ Slovenská ornitologická spoločnost'/BirdLife Slovensko, Námestie osloboditel'ov 1, 07101 Michalovce, \\ Slovakia; *e-mail: matejrepel@gmail.com \\ ${ }^{2}$ J. Hollého 111, 07101 Michalovce, Slovakia
}

\begin{abstract}
The first breeding attempt of the Alpine Swift (Tachymarptis melba) in Slovakia is documented and range and population trend in Europe discussed. Four specimens of the species had appeared during the breeding season 2021 in Michalovce town, SE Slovakia, and a nest with the Alpine Swift eggs was documented on an unaccomplished panel building at a height of $22 \mathrm{~m}$. The Alpine Swifts left the breeding site individually between September 27 and October 18. This breeding may be related to the increase of European population of Alpine Swift.
\end{abstract}

Key words: Alpine Swift, breeding, Slovakia, Central Europe

Dážd'ovník skalný (Tachymarptis melba Linnaeus, 1758) je polytypický druh s 10 poddruhmi rozšírenými naprieč ,starým svetom“, z ktorých sa nominátny poddruh melba vyskytuje v južnej Európe, severnom Maroku, Malej Ázii a Iráne (Chantler et al. 2020). Podl'a Červeného zoznamu IUCN je hodnotený ako menej dotknutý (LC; BirdLife International 2021). Areál druhu s indo-africkým rozšírením je rozptýlený od južnej a východnej Afriky a Madagaskaru po severné oblasti Álp, vo východnej časti po Himaláje, Indiu a Srí Lanku (Kropil 2002; obr. 1). Väčšina európskych dážd'ovníkov hniezdi na stredomorskom pobreží, v horách a skalnatých oblastiach južnej Európy vrátane Pyrenejí, Álp a Balkánu najmä v nadmorských výškach medzi 400 a 1700 m n. m. (Boano \& Delov 1997), ale zistené boli hniezdiská až do nadmorskej výšky 2300 m (Glutz von Boltzheim \& Bauer 1980, Mingozzi et al. 1988). Boano (2020) uvádza v porovnaní s Boano \& Delov (1997) viac záznamov v Turecku a viac potvrdených hniezdnych

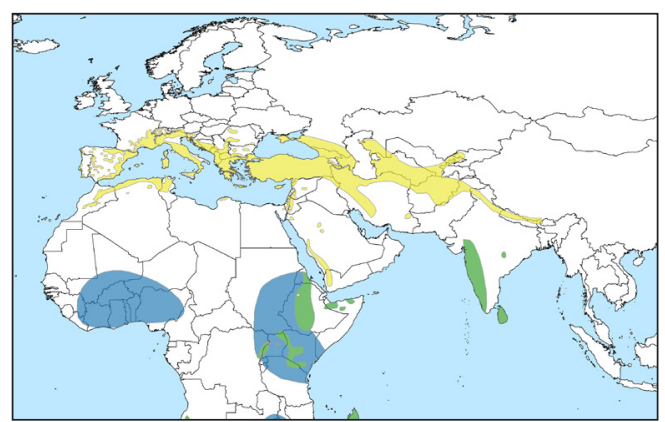

Obr. 1. Hniezdne rozšírenie a zimoviská Tachymarptis melba. Žltá = prirodzený hniezdny areál, modrá = celeoročný nehniezdny výskyt, zelená = celoročný prirodzený výskyt. Zdroj: BirdLife International and Handbook of the Birds of the World (2020).

Fig. 1. Breeding and winter range of Tachymarptis melba. Yellow = native breeding range, blue = native non-breeding, green = native resident. Source: BirdLife International and Handbook of the Birds of the World (2020). 
lokalít v Kaspickom regióne a na Kryme. Doposial' najsevernejšie známe hniezdne lokality sú v Štrasburgu (Francúzsko, 48³5'N) a Karlsruhe (Nemecko, 490'33“N) (Boano 2020, Schlenker 2021, Charenton 2021).

Najmä na severných a južných úbočiach Álp druh bežne hniezdi v sídlach, historických budovách a mostoch aj v malých nadmorských výškach (Knaus et al. 2018). Hoci bolo hniezdenie dážd'ovníkov skalných v l'udských sídlach známe od 17. storočia, táto tendencia synantropizácie druhu je zjavná najmä od 90-tych rokov 20. storočia (Boano 2020). Viac ako $80 \%$ švajčiarskej populácie hniezdi v budovách, viac ako 80 talianskych miest je osídlených dážd'ovníkom skalným a napríklad v španielskej Barcelone hniezdia tisíce párov. Roztrúsene hniezdi najbližšie $\mathrm{k}$ východnému Slovensku na území Rumunska (Boano 2020). Vo všeobecnosti sa populácia v Európe považuje za stabilnú alebo rastúcu (Boano 2020).

Pri porovnaní mapy hniezdneho rozšírenia v Európe s odstupom približne 30 rokov (Boano 2020) môžeme pozorovat' posun hranice mierne na sever vo Francúzsku a Nemecku, ale tiež v Rumunsku smerom na západ do Panónskej panvy a na sever k ukrajinským hraniciam. Rozširovanie hniezdneho areálu na sever a do Panónskej panvy potvrdzujú aj najnovšie údaje z Ukrajiny a Mad'arska. V meste Kosiv $\left(48^{\circ} 19^{\circ} \mathrm{N}, 25^{\circ} 5.5^{\circ} \mathrm{E}\right)$ na juhu IvanoFrankivskej oblasti na severnom úpätí Karpát sa zistilo v roku 2020 úspešné hniezdenie 3 - 4 párov (Grygorchuk et al. 2020). Dovtedy bolo hniezdenie druhu známe na Ukrajine len na Krymskom polostrove a najbližšie hniezdiská k mestu Kosiv sa nachádzali na severe Rumunska. Zahniezdili tiež na juhu Mad'arska v meste Segedín a v rokoch 2020 a 2021 zahniezdili aj v meste Debrecín $\left(47^{\circ} 32.5^{\circ} \mathrm{N}\right.$, $21^{\circ} 34^{`} \mathrm{E}$ ), kde bolo 22. 8. 2020 na hniezdisku pozorovaných až 16 jedincov (Tóth 2020).

Európska populácia dážd'ovníka skalného zimuje v tropickej Afrike až po južnú Afriku (SCHRÖPFER 2008). Vzhl'adom k nízkemu počtu nálezov v tropickej Afrike nie sú zimoviská druhu a jednotlivých poddruhov dobre známe. Zálety po vyhniezdení alebo v dôsledku ne- priaznivého počasia sa zistili aj d'aleko na sever od hniezdneho areálu (Pol'sko, južné Nórsko, Vel'ká Británia, Shetlandské a Orknejské ostrovy, dokonca Island) (Glutz von Boltzheim \& Bauer 1980, ScHRÖPFER 2008, eBird 2021). V Európe sa druh od roku 1804 zaznamenal mimo hniezdneho areálu najmenej v 11 krajinách (Tarsiger.com 2021), a to desiatky záznamov v Spojenom Král'ovstve a Severnom Írsku, Švédsko 50 záznamov, Dánsko 37, Belgicko 37, Nórsko 20, Pol'sko 14, Island 5, Fínsko 4, Litva 2, Estónsko 1, Bielorusko 1. V Európe je hlavným odletovým termínom september, kedy sa môžu mladé jedince objavit' aj 1000 km od svojich hniezdisk a posledné záznamy sú zvyčajne z polovice októbra, na jar sa objavujú od konca marca (Glutz von Boltzheim \& Bauer 1980). Doposial' sa dážd'ovník skalný vyskytoval na Slovensku a Čechách vel'mi vzácne. V roku 1963 bol jeden so švajčiarskym krúžkom zistený v západných Čechách a jeden nájdený mumifikovaný $\mathrm{v}$ obilnom sile v Piešt’anoch v roku 1974. Oba pochádzali zo známeho hniezdiska v Solothurne, zaleteli do vzdialenosti $473 \mathrm{~km}$ resp. $780 \mathrm{~km} \mathrm{SV} \mathrm{smerom}$ mimo areál hniezdneho rozšírenia (Schröpfer 2008). Zo Slovenska boli Faunistickou komisiou SOS/BirdLife Slovensko akceptované ešte dva staršie údaje, v septembri 1949 v sedle Váhy pod Rysmi vo Vysokých Tatrách a v lete 1955 kŕdel' vo Vysokých Tatrách na konci Javorovej doliny (Kropil 2002). Okrem toho sa nachádza niekol'ko jedincov nejasného pôvodu v zbierkach Podtatranského múzea v Poprade a Slovenského národného múzea v Bratislave (Ferianc 1979). Kropil (2002) konštatuje, že za obdobie 1980 - 1999 nebol jeho výskyt u nás zaznamenaný.

Výskyt dážd'ovníka skalného na Slovensku po roku 1974 sa podarilo zaznamenat' a zdokumentovat' až v roku 2018 (Kvetko et al. 2019) -3. septembra začul P. Chrašč v Michalovciach (Nám. osloboditel’ov) neznámy hlas vtáka (17:05 hod), kedy sa pozorovali a fotograficky zdokumentovali 2 jedince, ktoré odleteli južným smerom (sídlisko Východ). Približne o pol hodinu sa opät' objavili a odleteli smerom na sever (sídlisko SNP). Ďalšie pozorovania (zakaždým 
1 ex.) na rovnakej lokalite boli až o 2 roky (20., 21. a 24. augusta 2020) počas monitoringu jesennej migrácie vtákov zo strechy budovy (tzv. Družstevný dom, Nám. osloboditel'ov). Tieto pozorovania vzbudili podozrenie, či nejde o hniezdiace jedince. V roku 2021 sme sa rozhodli našu hypotézu overit' a hned' pri prvom pokuse o monitoring zo strechy budovy na rovnakej adrese bol 10.6. 2021 pozorovaný 1 ex. Dňa 11. 6. 2021 sa v Michalovciach na sídlisku SNP, ul. Púpavová (4845'55.542"N, $21^{\circ} 55^{\prime} 6.923^{\prime \prime E}$ ) dohl'adala budova (obr. 2a, b), kde boli za 4 hodiny pozorované dážd'ovníky $6 \times$, pričom boli zaznamenané minimálne 3 jedince, zaletujúce do štrbín medzi panelmi, a do jednej z nich opakovane až $3 \times$ (obr. 2a, b). Hniezdnu lokalitu tvorila hrubá stavba 8-poschodového panelového domu, ktorý bol rozostavaný v roku 1989, no doposial' zostal nedokončený. Dážd'ovníky nalietavali na dve steny panelového domu bez okien (obr. 2a, b) orientované SSV smerom (geodetický azimut $20^{\circ}$ ). Panelový dom je situovaný na okraji Michaloviec v obkolesení obývaných panelových domov, ale pred stenou s hniezdiacimi dážd'ovníkmi je vol'né priestranstvo bez d'alších budov.

Následne, v priebehu júna - októbra, boli zaznamenávané jedince dážd'ovníkov skalných opakovane, pričom najviac pozorovaní bolo podvečer, ked' tam prilietali po západe slnka nocovat'. Prílety do horizontálnych, ale ojedinele aj vertikálnych štrbín boli sprevádzané väčšinou viacerými náletmi, ktoré opakovali vo vel'kých oblúkoch a pritom sa hlasno ozývali. Cez deň bolo potrebné čakat' na prílet aj hodinu. Opakované zálety do štrbín na rovnakých miestach a trvalý výskyt na vhodnej lokalite v hniezdnom období dávali predpoklad, že tu pravdepodobne hniezdia. Súčasne ale boli pozorované najviac 4 jedince a preto boli aj pochybnosti, či tu naozaj hniezdia. Dňa 2. 8. 2021 sa realizovala fyzická kontrola predpokladanej hniezdnej steny. Dva jedince dážd’ovníka skalného počas kontroly nalietavali do blízkosti pracovníka visiaceho zo strechy paneláku na lanách, pričom sa hlasno ozývali a z fotografií sa podarilo zistit', že jeden z nich mal v zobáku
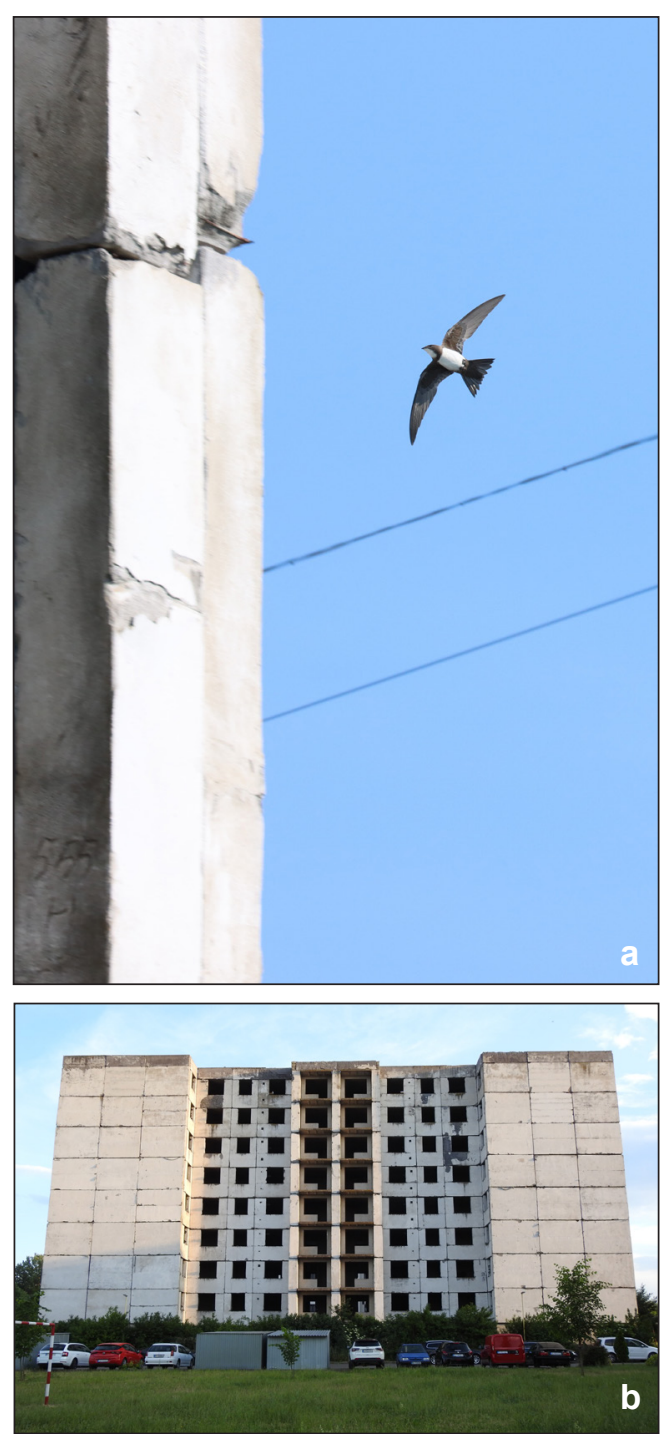

Obr. 2. Jedinec Tachymarptis melba (a) a hniezdna lokalita (nedokončená stavba panelového domu z r. 1989; b) $\checkmark$ Michalovciach, JV Slovensko (foto: M. Repel).

Fig. 2. The specimen of the Tachymarptis melba (a) and the breeding site (unaccomplished panel building; $b$ ), Michalovce, SE Slovakia (photo by M. Repel).

väčšie biele pierko, pravdepodobne ako výstelku do hniezda. V štrbinách boli nájdené viaceré hniezda dážd'ovníkov obyčajných (Apus apus), ktoré už v tom období takmer všetky opustili hniezdnu lokalitu, aj so zachladnutými vajíčkami a ešte jedným vel'kým mlád'at'om tesne pred vyletením z hniezda. Identifikované boli 

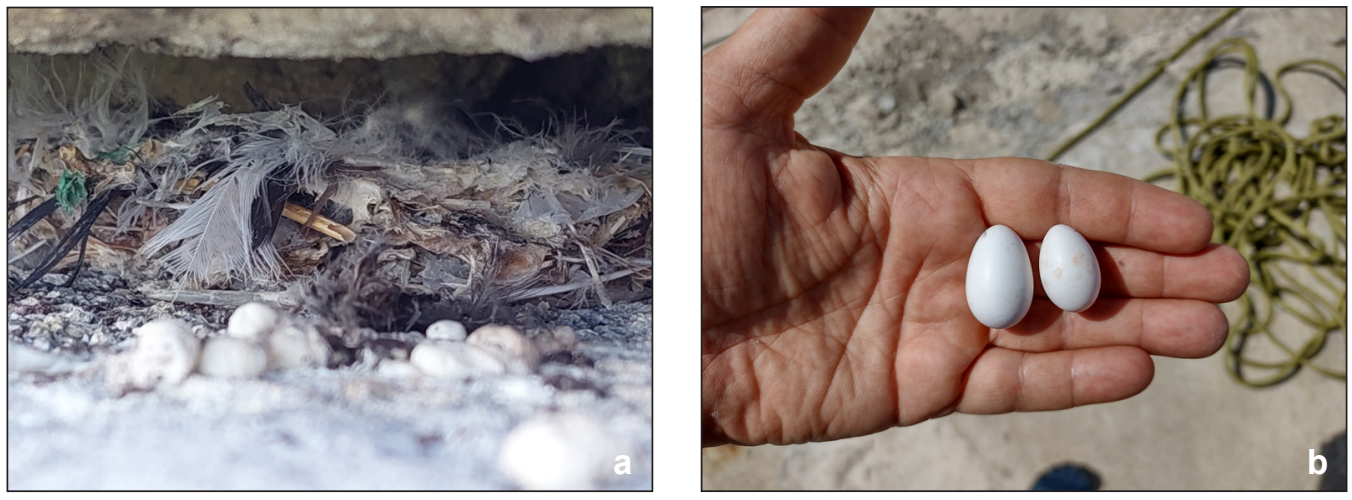

Obr. 3. Hniezdo dážd’ovníka skalného (Tachymarptis melba) (a) a vajíčko (b) s rozmermi 28,7 mm × 18,7 mm (vlavo) v porovnaní s vajíčkom dáždovníka obyčajného (Apus apus) s rozmermi 24,3 mm × 16,1 mm (vpravo); Michalovce, 2. 8. 2021 (foto: M. Novotný (a) a M. Repel (b)).

Fig. 3. The nest (a) of the Alpine Swift (Tachymarptis melba) and its egg (b) with diameter $28.7 \mathrm{~mm} \times 18.7 \mathrm{~mm}$ (left) compared to the egg of the Common Swift (Apus apus) with diameter $24.3 \mathrm{~mm} \times 16.1 \mathrm{~mm}$ (right), Michalovce, August 8, 2021 (photo by M. Novotný (a) and M. Repel (b)).

aj 2 hniezda patriace pravdepodobne dážd'ovníkovi skalnému, čo sme usúdili podl'a vel'kosti hniezda, väčšieho množstva hniezdneho materiálu a o niečo bohatšej výstelky pozostávajúcej z pozliepaných pierok, trusu a slamky (obr. 3a). Nachádzali sa v horizontálnych štrbinách medzi panelmi vo výške približne 20 - $25 \mathrm{~m}$ - nad 6 . a 7. podlažím 8-poschodového domu. V jednom z hniezd sa nachádzali 3 vajíčka. Jedno z nich bolo zdokumentované (obr. 3 b) s rozmermi 28,7 $\mathrm{mm} \times 18,7 \mathrm{~mm}$. Glutz von Boltzheim \& Bauer (1980) zistili na vzorke 456 vajec z hniezdnej lokality vo Švajčiarsku dĺžku vajec od $26,5 \mathrm{~mm}$ do $35,0 \mathrm{~mm}$ a šírku od $16,9 \mathrm{~mm}$ do $21,3 \mathrm{~mm}$, priemerné rozmery $30,46 \mathrm{~mm} \times 19,19 \mathrm{~mm}$. Pri porovnaní s vajíčkom dážd'ovníka obyčajného priamo z lokality $(24,3 \mathrm{~mm} \times 16,1 \mathrm{~mm})$ ako aj s literárnymi údajmi $(25,1 \mathrm{~mm} \times 16,1 \mathrm{~mm}$, $\mathrm{n}=175$, Pellantová 1975) sa potvrdilo, že zdokumentované vajíčko patrilo dážd'ovníkovi skalnému. Vzhl'adom na pomerne neskorý dátum kontroly hniezda s vajíčkami (2. august) sme nepredpokladali, že sa mlád'atá ešte vyliahnu a stihnú úspešne opustit' hniezdo, čo potvrdili aj následné pozorovania a dokumentácia. Počas celej sezóny (jún - október) sme pozorovali najviac 4 jedince, na fotografiách sme nezaznamenali vylietané mlád'atá, ani dospelce s typicky zväčšeným hrvol'om, v ktorom prinášajú mlád’atám potravu na hniezdo. Zaznamenali sme tak síce neúspešné, no nap- riek tomu prvé doložené hniezdenie druhu na Slovensku. Súradnice hniezdnej lokality sú $48^{\circ} 45^{\prime} 56^{\prime \prime} \mathrm{N}, 21^{\circ} 55^{\prime} 7^{\prime \prime} \mathrm{E}$, čo je len o približne 14‘ južnejšie (necelých $6 \mathrm{~km}$ ) ako najsevernejšie známe hniezdisko v Karlsruhe v Nemecku (490‘33“N, 8²4‘41“"E; Schlenker 2021). Najbližšie známe hniezdiská sa nachádzajú 140 km južnejšie v Panónskej panve (Debrecín, Mad'arsko; Tóth 2020) a 240 km východne na vonkajšej strane Karpatského oblúka (Kosiv, Ukrajina; Grygorchuk 2020). Domnievame sa, že michalovské dážd'ovníky patria do populácie postupne sa rozširujúcej z hniezdisk v Rumunsku, ale údaj z Ukrajiny dokazuje, že prekročili už aj Karpaty. Na budove panelového domu v Michalovciach sa spoločne s dážd'ovníkom skalným zistilo hniezdenie minimálne 30 párov dážd’ovníkov obyčajných (Apus apus), 5 párov vrabcov pol'ných (Passer montanus), 2-3 páry žltochvosta domového (Phoenicurus ochruros), 1 pár trasochvosta bieleho (Motacilla alba) a budovu využívali na hniezdenie mestské holuby (Columba livia domestica).

Pri monitoringu jedincov sme sa zamerali aj na zaznamenanie odletu dážd'ovníka skalného na jesennú t’ahovú cestu z jeho novoobjaveného hniezdiska v Michalovciach. Európska populácia opúšt’a hniezdiská zvyčajne v polovici októbra, ale extrémne neskoré záznamy sú aj z novembra a decembra (Boano 2020). Dážd'ovníky sme monitorovali večer, pričom 
sa zaznamenával počet jedincov nocujúcich v štrbinách panelového domu. Na lokalitu prilietali vtáky zvyčajne niekol'ko minút pred zotmením a zanocovaním, pričom ešte vo vel'kých oblúkoch oblietali bytovku, kým zaleteli do štrbín medzi panelmi, zakaždým na rovnakých miestach. Začiatok nocovania sa posúval v čase na skoršiu hodinu spolu so skorším súmrakom. V prvej dekáde septembra vtáky zanocovali medzi 19:40 - 19:28, v druhej dekáde medzi 19:14 - 19:05, v tretej dekáde septembra medzi 18:49 -18:23 s jednou výnimkou 27. 9. 2021, kedy lietali, za jasného teplého počasia, takmer do zotmenia, do 19:38 hod. V októbri sa prílety na nocovisko d'alej posúvali v čase na skoršiu hodinu postupne od 18:34 až do 17:38 dňa 17. 10. 2021. Niekol'ko krát sa po neskoršom príchode na lokalitu podarilo prítomnost' vtákov na lokalite potvrdit' len vd'aka hlasovým prejavom vyprovokovaných reprodukciou hlasu z mobilného telefónu, ked' už boli vtáky na noc v štrbinách (napr. 30. 9. o 18:18, 12. 10. o 17:58). Vtáky opúšt’ali hniezdnu lokalitu v Michalovciach postupne. Prvý zo štvorice odletel pravdepodobne 27. 9. 2021 (26. 9. nocovali 4 jedince, od 27.9. a neskôr sa zistili už len 3 jedince), druhý 4. 10. 2021, tretí medzi 7. a 12. októbrom, posledný jedinec na lokalite nocoval ešte 17. 10. 2021 a odletel pravdepodobne na druhý deň 18.10.2021. V d'alších dňoch (18., 20. 22. 27. október) už pozorovaný nebol.

\section{Pod'akovanie}

Za výškové práce pri kontrole hniezd d'akujeme Milanovi Novotnému, za asistenciu a pomoc pri výškových prácach Petrovi Havašovi, za terénnu spoluprácu Matejovi Repelovi ml., Petrovi Pristašovi, Jánovi Dobšovičovi, Richardovi Schnürmacherovi, účastníkom Letného ornitologického tábora v Sennom, za pomoc pri monitoringu a asistenciu pri písaní článku môjmu synovi Matejovi a za podporu mojej tolerantnej manželke Ad'ke.

\section{Literatúra}

BirdLife InTERnATIONAL \& HANDBoOK OF THE Birds of THE WORLD 2020: Bird species distribution maps of the world. Version 2020.1. — http://datazone.birdlife. org/species/requestdis. Navštívené 24. 9. 2021.

BirdLife International (2021) Species factsheet: $\mathrm{Ta}$ chymarptis melba. - http://www.birdlife.org. Navštívené 20. 12. 2021.

BoAno G. 2020: Tachymarptis melba. Alpine swift. Pp.: 199. In: Keller V., Herrando S., Voříšek P., Franch M., Kipson M., Milanesi P., Martí D., Anton M., Klvañová A., Kalyakin M. V., Bauer H.-G. \& FoPPEN R. P. B. (eds.): European Breeding Bird Atlas 2: Distribution, Abundance and Change. - European Bird Census Concil and Lynx Edicions, Barcelona.

Boano G. \& Delov V.. 1997: Apus Melba. Alpine Swift. - Pp.: 429. In: Hagemeijer W. J. M. \& Blair M. J. (eds.): The EBCC Atlas of European Breeding Birds: Their Distribution and Abundance. T. \& A.D. Poyser, London.

Chantler P., de Juana E., Kirwan G. M. \& Boesman P. F. D. 2020: Alpine Swift (Apus melba), version 1.0. In del Hoyo J., Elliott A., Sargatal J., Christie D. A. \& DE JuAna E. (eds.): Birds of the World. - Cornell Lab of Ornithology, Ithaca, New York. https://doi. org/10.2173/bow.alpswi1.01. Navštívené 31. 1. 2022

Charenton C. 2021: eBird Checklist: Alpine Swift: https://ebird.org/checklist/S91215436. eBird: An online database of bird distribution and abundance [web application]. eBird, Ithaca, New York. — http:// www.ebird.org. Navštívené 31. 1. 2022.

EBIRD 2021: eBird: An online database of bird distribution and abundance [web application]. eBird, Cornell Lab of Ornithology, Ithaca, New York. - http://www. ebird.org. Navštívené 31. 1. 2022

FERIANC O. 1979: Vtáky Slovenska 2. — Veda, Bratislava. Glutz von Boltzheim N. \& Bauer K. M. 1980: Apus melba (Linnaeus 1758) - Alpensegler. - Pp.: 712-732. In: Handbuch der Vögel Mitteleuropas, Band 9/II. Columbiformes - Piciformes. AULA-Verlag, Wiesbaden.

Grygorchuk A. A., Drebet M. V. \& Martyniuk V. Ju. 2020: Breeding of the Alpine Swift (Tachymarptis melba) in the town of Kosiv (Ivano-Frankivsk region West Ukraine). — Berkut, 29 (1-2): 68-69.

Hagemeijer W. J. M. \& Blair M. J. 1997: The EBCC Atlas of European Breeding Birds: Their Distribution and Abundance. - T. \& A.D. Poyser, London.

Knaus P., Antoniazza S., Wechsler S., Guélat J., Kéry M., Strebel N. \& SATtler T. 2018: Schweizer Brutvogeatlas 2013-2016. - Schweizerische Vogelwarte, Sempach.

Kropil R. 2002: Dážd'ovník skalný (Apus melba). — Pp.: 
385. In: Danko Š., DarolovÁ A. \& Krištín A. (eds.): Rozšírenie vtákov na Slovensku. — Veda, Bratislava.

Kvetko R., Mojžiš M., Harvančík S., Karaska D., OleKŠÁK M., ŠRANK V. \& JUREČEK R. 2019: 19. správa Faunistickej komisie Slovenskej ornitologickej spoločnosti/BirdLife Slovensko. - Tichodroma 31: 49-55.

Mingozzi T., Boano G. \& Pulcher C. 1988: Atlante degli Uccelli Nidificanti in Piemonte e Val d'Aosta 1980-1984. - Monografie 8, Museo Regionale di Scienze Naturali, Torino.

Pellantová J. 1975: The course of breeding of the Swift (Apus apus Linn.). - Zoologické Listy 24: 249-262. Schlenker H. 2021: eBird Checklist: Alpine Swift: https://ebird.org/checklist/S91779251. eBird: An online database of bird distribution and abundance [web application]. eBird, Ithaca, New York. — http:// www.ebird.org. Navštívené 31. 1. 2022.

SCHRÖPfer L.2008: Rorýs velký. —- Pp.: 321-322. In: CEPÁK J., KLVAŇA P., ŠKopeK J., SCHRÖPfER L., JelíNEK M., HoŘÁK D., FormáneK J. \& ZÁrybnickÝ J. (eds.): Atlas migrace ptáků České republiky a Slovenska. Aventinum, Praha.

TARSIGER.COM 2021: Finland's most popular bird pages. - http://www.tarsiger.com/home/index. php?sp=\&lang=eng. Navštívené 20.12.2021.

Tóтн Z. 2020: Havasi sarlósfecske - Tachymarptis melba - http://birding.hu/megfigyeles/adatlap/753066. Navštívené 31. 1. 2022.

Došlo: 31. 1. 2022

Prijaté: 14. 2. 2022

Online: 17. 2. 2022 